\title{
Design and experimental study of a multi-modal piezoelectric energy harvester
}

DOI:

10.1007/s12206-016-1202-6

\section{Document Version}

Accepted author manuscript

Link to publication record in Manchester Research Explorer

\section{Citation for published version (APA):}

Xiong, X., \& Oyadiji, S. O. (2017). Design and experimental study of a multi-modal piezoelectric energy harvester. Journal of Mechanical Science and Technology, 31(1), 5-15. https://doi.org/10.1007/s12206-016-1202-6

\section{Published in:}

Journal of Mechanical Science and Technology

\section{Citing this paper}

Please note that where the full-text provided on Manchester Research Explorer is the Author Accepted Manuscript or Proof version this may differ from the final Published version. If citing, it is advised that you check and use the publisher's definitive version.

\section{General rights}

Copyright and moral rights for the publications made accessible in the Research Explorer are retained by the authors and/or other copyright owners and it is a condition of accessing publications that users recognise and abide by the legal requirements associated with these rights.

\section{Takedown policy}

If you believe that this document breaches copyright please refer to the University of Manchester's Takedown Procedures [http://man.ac.uk/04Y6Bo] or contact uml.scholarlycommunications@manchester.ac.uk providing relevant details, so we can investigate your claim.

\section{OPEN ACCESS}




\title{
Design and experimental study of a multi-modal piezoelectric energy harvester
} Xingyu Xiong ${ }^{1, *}$ and S. Olutunde Oyadiji ${ }^{2}$

${ }^{1}$ School of Energy, Power and Mechanical Engineering, North China Electric Power University, Changping District, Beijing, 102206, China

${ }^{2}$ School of Mechanical, Aerospace and Civil Engineering, The University of Manchester, Manchester, M13 9PL, UK

\begin{abstract}
A multi-modal pie zoelectric vibration energy harvester is designed in this article. It consists of a cantilevered base beam and some upper and lower layer beams with rigid masses bonded between the beams as spacers. For a four-layer harvester subjected to random base excitations, relocating the mass positions leads to the generation of up to four close resonance frequencies over the frequency range from $10 \mathrm{~Hz}$ to $100 \mathrm{~Hz}$ with relative large power output. The harvesters are connected with a resistance decade box and the frequency response functions of the voltage and power on resistive loads are determined. The experimental results are validated with the simulation results using the finite element method. On a certain level of power output, the experimental results show that the multi-modal harvesters can generate a frequency band that is more than two times greater than the frequency band produced by a cantilevered beam harvester.
\end{abstract}

Keywords: Piezoelectric; Vibration; Energy harvesting; Broadband; Multi-modal

\section{Introduction}

For the development of structural healthy monitoring strategies, there is a current need to harvest small-scale ambient energy for the self-powered, batteryless wireless sensor nodes [1]. Harvesting the vibration energy from resonance has drawn much attention since it has good potential to provide adequate power. Piezoelectric materials are used to convert mechanical strain energy into electrical energy [2-5]. For the cantilevered harvester, normally the fundamental mode is used. The remaining higher modes are not only far away from the first mode, they also generate much lower power outputs. To overcome the limitations of cantilevered harvesters, multimodal harvesters, which generate multiple vibration modes with relatively large power output in a broader frequency band, are developed to improve the broadband performance.

The harvesters with array of beams structure can achieve close multiple resonances [6-9]. They normally consist of several individual beam structures, which are physically decoupled whereas several piezoelectric components bonded on the cantilevered beams are electrically connected. The advantage for this is that the fundamental modes of individual beams can be tuned easily to generate close resonance frequencies and nearly same level of power outputs. However, when one cantilevered beam is working under its resonance frequency, the remaining beams are barely active. This could significantly affect the power density of the harvesters if too many beams are used. Besides, since a large part of the piezoelectric layer bonded on these

\footnotetext{
* Corresponding author. Tel.: +86 61772297, Fax.: +86 61772297
}

E-mail address:xingyu.xiong@ncepu.edu.cn 
passive beams only undergoes small strains, the electromechanical coupling of the harvester is decreased.

The dual-mass harvesters are widely reported multi-modal harvesters [10-13]. It normally consists of two parts of massspring or mass-beam structures. The interaction of the two parts can generate the first two transverse vibration modes with close resonance frequencies. However, the dual-mass harvester only generates two close modes, which still have limited broadband performance. Apart from the dual-mass harvesters, there are some other multi-modal designs that have been reported in existing literature, such as L-shaped [14], Zigzag-shaped [15, 16], M-shaped [17] and H-shaped [18] harvesters. In fact, using coupled multi-modal structures to generate relative large power output around every mode and effectively broaden the bandwidth is a tough task. In many investigations, although the resonance frequencies of the harvesters are enough close, one or more vibration modes can be dominant. This significantly affects the broadband performance since the performance of the remaining modes is reduced. This is clearly due to the lack of proper design.

In this paper, a multi-modal harvester, which can generate up to four close resonance frequencies over the frequency range from $10 \mathrm{~Hz}$ to $100 \mathrm{~Hz}$ with relative large power output, is designed and experimentally tested. The harvester consisting of a base cantilevered beam that is connected to some upper and lower layer beams by spacers. Rigid masses are attached to each layer to tune the resonance frequencies of the harvester and these masses also serves as the spacers. By varying the positions of the masses, the harvester can generate close resonance frequencies and considerable power output in the multiple modes. This paper is organised into seven sections. Sec. 2 is a brief introduction on harvester modelling us ing a general distributed electromechanical parameter model with the utilization of the Finite element analysis (FEA) technique. Sec. 3 is on multi-modal harvester design and development. Sec. 4 is on configurational optimisation strategy of multi-layer harvesters. Sec. 5 is on the introduction of experimental test setup. Sec. 6 is on experimental study of the performance of multi-modal harvesters. The last section presents the conclusions of this paper.

\section{Vibration energy harvesting model}

The modal analysis technique can be used to represent the steady-state linear vibration response of a harvester model that is subjected to continuous harmonic excitation. The displacement of the transverse vibration relative to the moving base of the harvester at time $t$ is:

$$
\mathrm{u}_{r e l}(t)=\sum_{r=1}^{\infty} \phi_{r} \eta_{r}(t)
$$

where $\phi_{r}$ is the mass-normalised eigenfunction and $\eta_{r}(t)$ is the corresponding modal coordinates of the $\mathrm{r}^{\text {th }}$ mode. The equations governing the vibration modal response and electrical behaviour of the harvester model with a resistive load are given as:

$\frac{\mathrm{d}^{2} \eta_{r}(t)}{\mathrm{d} t^{2}}+2 \zeta_{r} \omega_{r} \frac{\mathrm{d} \eta_{r}(t)}{\mathrm{d} t}+\omega_{r}^{2} \eta_{r}(t)+\chi_{r} v(t)=F_{r}(t)$ 
$\frac{v(t)}{R_{l}}+\mathrm{C}_{p} \frac{d v(t)}{d t}-\sum_{r=1}^{\infty} \chi_{r} \frac{\mathrm{d} \eta_{r}(t)}{\mathrm{d} t}=0$

where $\eta_{r}(t)$ is the corresponding modal coordinates of the $\mathrm{r}^{\text {th }}$ mode, $v$ is the generated voltage, $\zeta_{r}$ is the damping ratio, $\omega_{r}$ is angular resonance frequency, $\chi_{r}$ is the modal electromechanical coupling term, $F_{r}$ is the modal mechanical forcing term, $\mathrm{C}_{p}$ is the piezoelectric capacitance and $R_{l}$ is the resistive load. The steady state solution of Eq. 2 is:

$\eta_{r}(t)=\frac{F_{r}-\chi_{r} v}{\omega_{r}^{2}-\omega^{2}+j 2 \zeta_{r} \omega_{r} \omega} e^{j \omega t}$

In fact, the derivations of the eigenfuction $\phi_{r}$, coupling term $\chi_{r}$, and $F_{r}$ can be tough and tedious when the configuration of the harvester is not uniform. Therefore, FEA software like ABAQUS and ANSYS are widely used at this stage to derive those parameters. For the short-circuit condition $(v=0)$ of the harvester with a harmonic base excitation $\mathrm{Y}_{0} \omega^{2} e^{j \omega t}$ at each resonance frequency, the absolute displacement relative to the moving base can be derived from the FEA results. Then, for the $\mathrm{r}^{\text {th }}$ mode, the forcing function $F_{r}$ determined from Eq. 4 in the frequency domain is given as follows:

$F_{r}=\left.2 \zeta_{r} \ddot{\mathrm{u}}_{r e l} \sqrt{m_{m r}}\right|_{\omega=\omega_{r}}$

where $m_{m}$ is the generalized modal mass. By replacing $v(t) / R_{l}$ with $i(t)$ in Eq.3, the complex current $i_{r}$ under the short-circuit condition can be derived from the FEA results and it is given by:

$i_{r}=\sum j \omega \chi_{r} \eta_{r}\left(j \omega_{r}\right)=\left.\sum_{r=1}^{\infty} \frac{j \omega F_{r} \chi_{r}}{\omega_{r}^{2}-\omega^{2}+j 2 \zeta_{r} \omega_{r} \omega}\right|_{\omega=\omega_{r}}$

Then, with the known $i_{r}$, the modal coupling term $\chi_{r}$ can be determined. The voltage across $R_{l}$ can be represented by [19]:

$v(\mathrm{t})=\frac{\sum_{r=1}^{\infty} \frac{j \omega F_{r} \chi_{r}}{\omega_{r}^{2}-\omega^{2}+j 2 \zeta_{r} \omega_{r} \omega}}{\sum_{r=1}^{\infty} \frac{j \omega \chi_{r}^{2}}{\omega_{r}^{2}-\omega^{2}+j 2 \zeta_{r} \omega_{r} \omega}+\frac{1}{R_{l}}+j \omega C_{p}} e^{j \omega t}$

The complex power in the frequency domain is $v(j \omega)\left(\frac{v(j \omega)}{R_{l}}\right)^{*}$ and the average power output is $|v|^{2} / 2 R_{l}$ (ignore electric losses). In this paper, the damping ratio $\zeta_{r}$ of each mode is experimentally derived.

\section{Design of multi-modal harvesters}

In this section, the configurations of the multi-modal harvesters designed for the experimental test are illustrated initially. A multi-modal harvester consists of a longer cantilevered base (see Fig. 1(a)), some shorter upper/lower layers (see Fig. 1(b)) and masses bonded between each pair of adjacent beams. Fig. 1(c) shows the simulation model of the twolayer two-mass harvester 2L2M-P05 developed by the commercial FEA software ABAQUS. As Fig. 1 shows, the effective length of the cantilevered base is $101 \mathrm{~mm}$, and the remaining part is clamped. A plate of the piezoelectric ceramic PZT is bonded near the clamped end of the base layer. There is a $1 \mathrm{~mm}$ gap between the PZT and the clamped end. All upper/lower layers and the 
masses have the same dimensions. The thickness and width of the masses are $12 \mathrm{~mm}$ and $9 \mathrm{~mm}$, respectively. The weight of each mass is 18.8 grams. Other properties of the harvester are given in Table 1.

In the experiment, for the convenience of fixing and moving the masses, there are ten groups of through holes on the upper/ lower layers and six groups of through holes on the base layer. Each mass also has two through holes and screws and nuts are used to bond the mass. In the simulation, the masses, screws and nuts are simplified into uniform masses of the magnitudes, which are equivalent to the total mass of the spacers and screws and nuts. There are ten possible mass positions and the sketch for numbering of mass positions is illustrated in Fig. 2. The positions of the masses from the free tip to the clamped end of the base layer are identified as Pabc-de, where $a, b$ and $c$ represent the positions of masses $M_{+1}, M_{+2}$ and $M_{+3}$ on the upper half and $d$ and $e$ represent the positions of masses $M_{-1}$ and $M_{-2}$ on the lower half by numbers from 0 to 9 . For example, the two-layer two-mass harvester $2 L 2 M$ given in Fig. 1(c) has the mass position P05 and the four-layer five-mass harvester 4L5M given in Fig. 4 has the mass position P391-09.

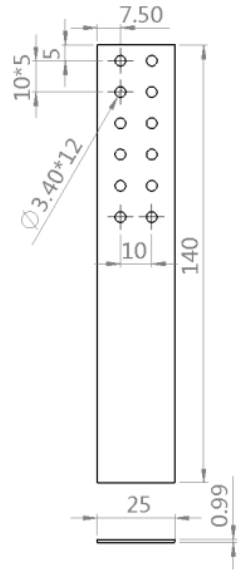

(a)

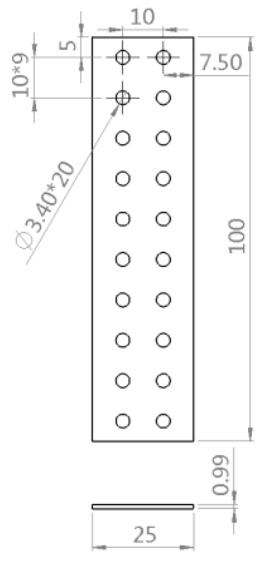

(b)

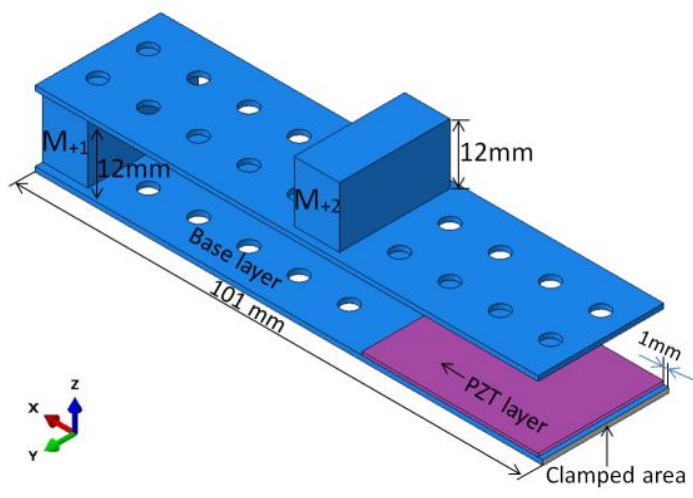

(c)

Figure 1: Sketches of (a) base layer (unit: $\mathrm{mm}$ ) and (b) upper/lower layer (unit: $\mathrm{mm}$ ) of the multi-layer harvesters, and (c) the simulation model of the two-layer two-mass harvester $2 L 2 M-P 05$.

Table 1: Properties of the multi-layer harvester

\begin{tabular}{l|l}
\hline Parameters & Properties \\
\hline Thickness of piezoelectric layer & $0.7 \mathrm{~mm}$ \\
\hline Length of piezoelectric layer & $34 \mathrm{~mm}$ \\
\hline Density of piezoelectric layer & $7800 \mathrm{~kg} / \mathrm{m}^{3}$ \\
\hline Clamped dielectric constant $\varepsilon_{33}^{S}$ & $1.1133 \times 10^{-8} \mathrm{~F} / \mathrm{m}$ \\
\hline Piezoelectric layer Young's modulus & $60.7 \times 10^{9} \mathrm{~N} / \mathrm{m}^{2}$ \\
\hline Piezoelectric constant $\mathrm{d}_{31}$ & $-210 \times 10^{-12} \mathrm{C} / \mathrm{N}$ \\
\hline Transverse coupling factor $\mathrm{k}_{31}$ & 0.38 \\
\hline Density of base/upper/lower layers & $7930 \mathrm{~kg} / \mathrm{m}^{3}$ \\
\hline Young's modulus of base layer & $200 \times 10^{9} \mathrm{~N} / \mathrm{m}^{2}$ \\
\hline Damping ratio & Measured \\
\hline
\end{tabular}




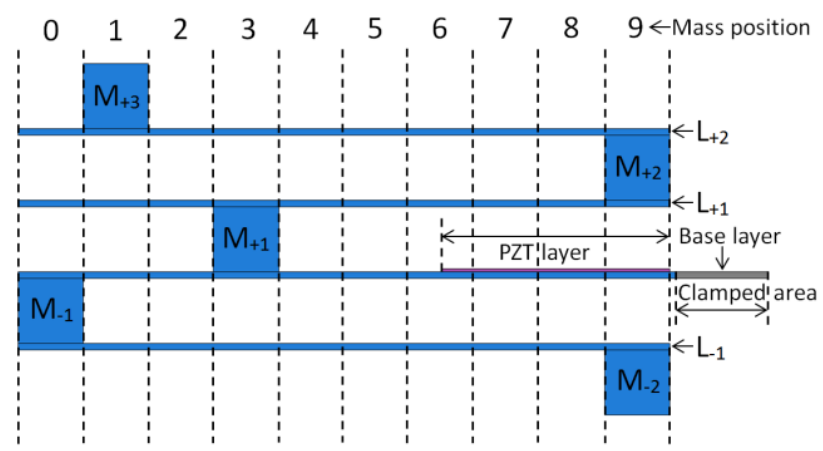

Figure 2: Sketch for numbering of mass positions (not the actual dimensions of the masses); four-layer five-mass model 4L5MP391-09; two upper layers and one lower layer are located on both sides of the base layer and the locations of masses on the upper half $\left(M_{+1}, M_{+2}, M_{+3}\right)$ is 391 and the lower half $\left(M_{-1}, M_{-2}\right)$ is 09 .

\section{Configurational optimisation strategy}

A modal approach was developed in a previous study where the two criteria of mass ratio and Electromechanical coupling coefficient (EMCC) were used to evaluate the modal mechanical and electromechanical performance of harvesters, respectively [13]. Mass ratio is defined as the percentage ratio of the effective mass to the total mass, which depends on the modal participation factor $g$ and represents how much mass of each mode effectively participates in the overall motion and the contribution of each mode to the maximum power output [3]. Mass ratio is introduced as $N_{r}=\gamma_{r}^{2} m_{r} / M$ where $N_{r}$ denotes the mass ratio for the $\mathrm{r}^{\text {th }}$ mode, $\gamma, m$ and $M$ are the modal participation factor, generalized modal mass and total mass, respectively. In fact, the natural frequencies and mass ratios can be determined directly by the FEA modal analysis. Since a multi-resonance harvester with good broadband performance requires close natural frequencies and relative large power output in each mode, an optimization strategy is developed to select the configurations with close resonances and favourable values of mass ratio initially. A structural screening process is developed using the mass ratio and frequency ratio as two filters to determine the configuration with optimal or near-optimal modal mechanical broadband performance (see Fig. 3), which obviates the need for full steady-state analysis in the first place.

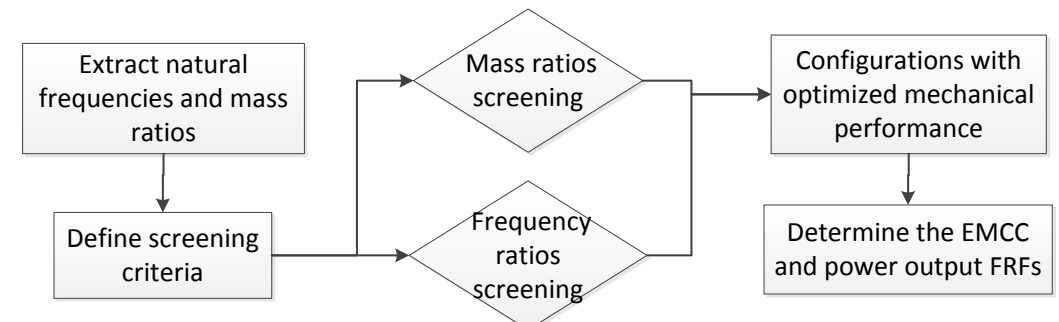

Figure 3: Flow chart of the structural screening process for configurational optimization of multi-resonance harvesters.

A previous studied structural screening result of the two-layer two-mass model 2L2M is given in Fig. 4 [13]. The shaded area is the selected mass positions of optimal or near-optimal configurations that meet the 
screening criteria frequency ratio $\mathrm{f} 2 / \mathrm{f} 1<2$ and mass ratio $\mathrm{N}>0.2$ in each mode. It should be noted that the screening result is based on the analysis presented in previous work using the original configurations. The original configurations are slightly different than the configurations used in this article. The base and upper/ lower layers of the original configuration have the same length $100 \mathrm{~mm}$ but they do not have through holes. The thickness and width of the masses are both $10 \mathrm{~mm}$, and the thickness and length of PZT layer are 0.5 $\mathrm{mm}$ and $25 \mathrm{~mm}$, respectively $\left(\mathrm{M}_{+1}=6\right.$ is unavailable in this article). In fact, experimental and simulated results provided in this article based on the modified configuration with through holes still follow the screening results based on the original configuration. More details about validating the structural screening results using experimental data will be discussed in the Secs. 6.1 and 6.2.

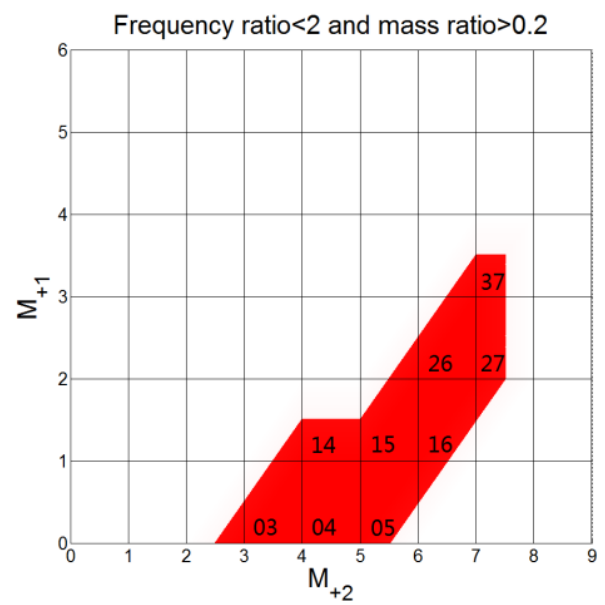

Figure 4: Result of structural screening for two-layer model (for the original configuration with no through hole in previous work [13]); the shaded area is the selected configurations meet the screening criteria $f 2 / f 1<2$, and $N_{l}$ and $\mathrm{N}_{2}>0.2$.

\section{Expe rimental test setup and procedure}

In this section, the experimental setup of the multi-modal harvesters is demonstrated. Fig. 5 shows the components and devices used in the experiment. Fig. 6 shows the flow chart of the experimental setup. The LMS TEST LAB 7A software and LMS SCADAS III data acquisition system are used to collect and process the experimental data. A built-in source panel in the software generate a random signal (band-limited white noise) to the power amplifier, which is the power supply of the electromagnetic shaker. Fig. 7 shows the measured random base excitation. The excitation level is controlled to preserve the linearity of the harvester dynamics. The clamped end of the base layer of the harvester is clamped between two stainless steel plates, which are mounted on the shaker. The mass of these plates helps to reduce the fundamental resonance frequency of the shaker. A piece of PZT plate (PIC151) is bonded on the base layer and connected to the resistance decade box. A PCB ICP accelerometer (sensitivity $99 \mathrm{mV} / \mathrm{g}$ ) is mounted on the base right above the clamped part of the harvester to measure the base excitation. The accelerometer is connected to a signal conditioner. A M5L/4 laser sensor (sensitivity $5.17 \mathrm{~V} / \mathrm{mm}$, resolution $1 \mu \mathrm{m}$ ) is used to measure the displacement of the harvester. The measured voltage data from the decade box, signal conditioner and the laser sensor are collected by the LMS data acquisition system. Since LMS system has $1 \mathrm{M} \Omega$ impedance and 
it is connected to the resistive load in parallel. Therefore, the actual resistive load on the harvester is less than the selected resistance of the decade box. The actual resistive load is determined as $1 / R_{\text {Load }}=1 / R_{R B O X}+$ $1 / \mathrm{R}_{\mathrm{LMS}}$.
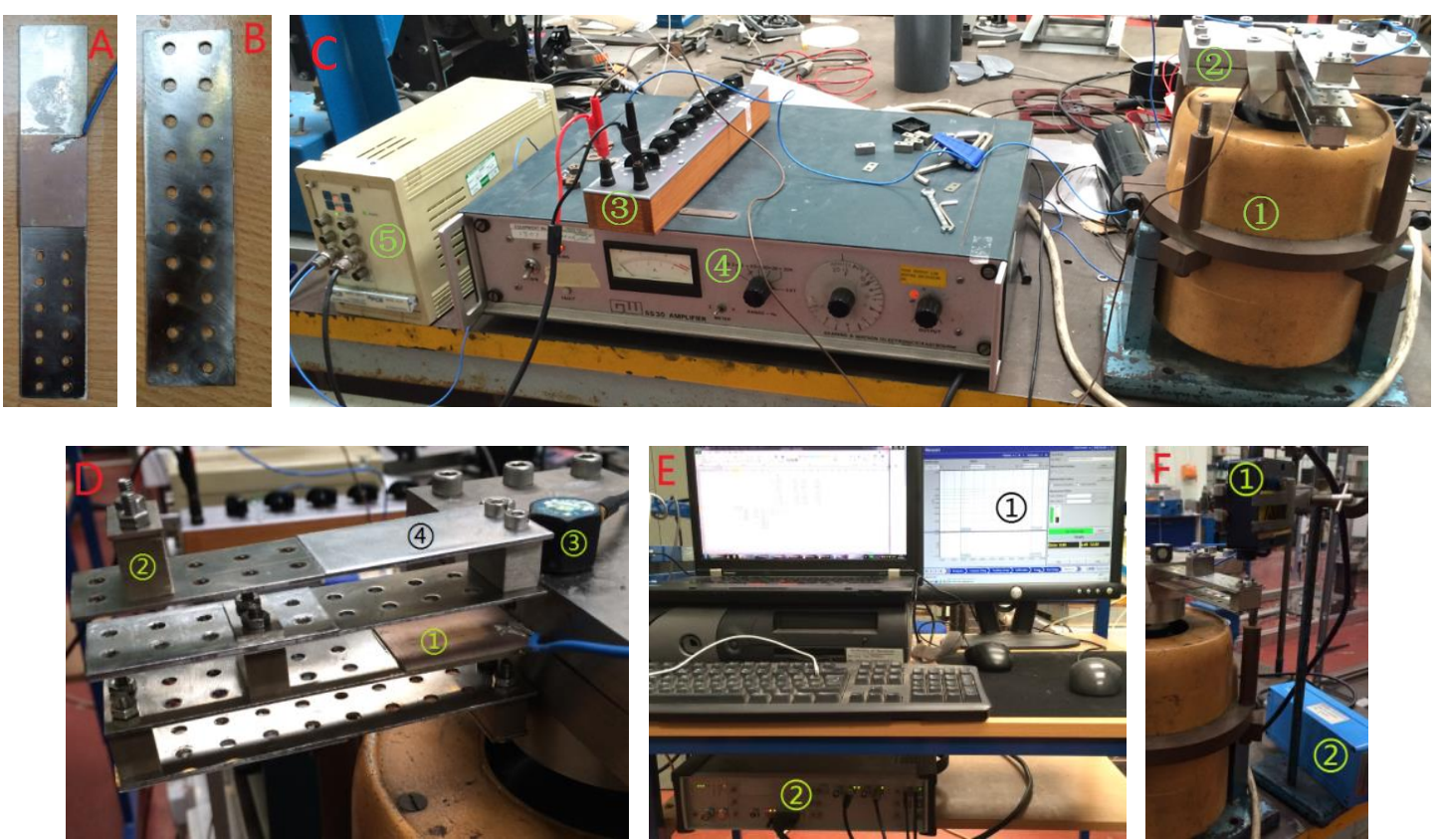

Figure 5: Experimental setup. A: the longer cantilevered base with bonded PZT layer. B: the upper/lower layer. C: (1) electromechanical shaker, (2) base to clamp the harvester, (3) resistance decade box, (4) power amplifier and (5) signal conditioner. D: (1) the four-layer five-mass harvester 4L5M-P391-09 and its PZT layer, (2) mass, screws and nuts, (3) ICP accelerometer mounted on the base and (4) damping foil. E: (1) LMS TEST LAB on PC and (2) LMS SCADAS III data acquisition system. F: (1) M5L/4 laser sensor head and (2) sensor monitor and power supply.

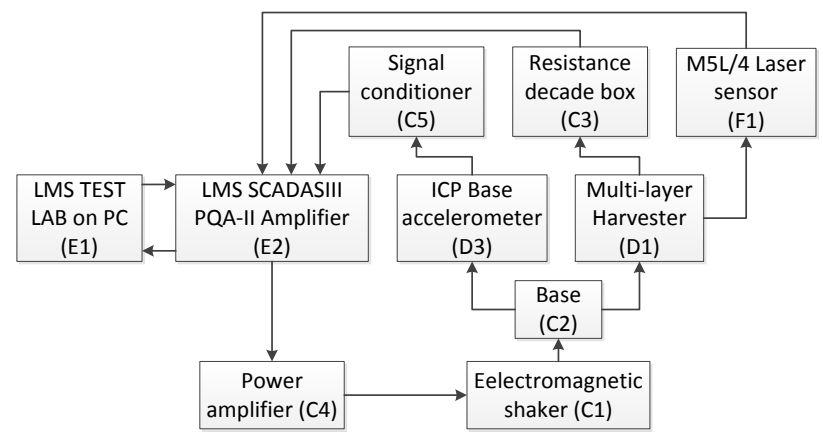

Figure 6: Flow chart of the experimental setup $(\mathrm{C} 1, \mathrm{C} 2 \ldots$ F1in brackets are shown in Figure 3). 


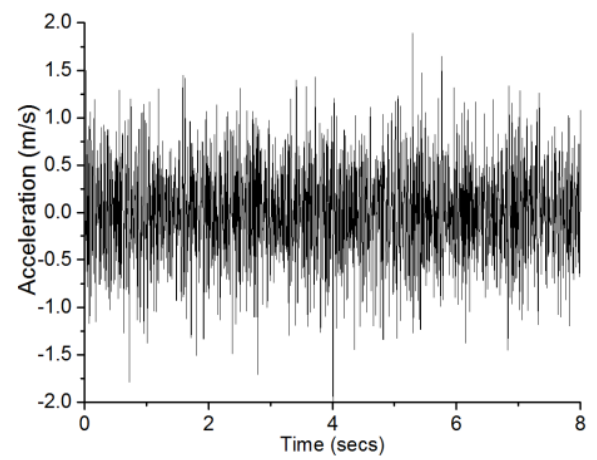

Figure 7: Measured base acceleration for random base excitation (white noise)

\section{Expe rimental validation of the performance of multi-modal harvesters}

\subsection{Two-layer harvester performance}

In this section, the experimental study of the two-layer harvester is presented. Fig. 8 shows the simulated and experimental power output FRFs with $100 \mathrm{k} \Omega$ resistive load for two-layer mode1 2L2M when the position of $\mathrm{M}_{+1}$ bonded on the base is 0 . It should be noted that the presented power output FRFs are normalised power for acceleration per $1 \mathrm{~m} / \mathrm{s} 2$. There is a good agreement between the simulated and experimental results for the trend of the FRFs when the mass positions are changed. For the experimental results, there are some noises around the anti-resonance frequencies and the damping is slightly greater than the simulated results. The reason could be because the random excitation causes some leakage in the signal processing and the amplitude is underestimated. Besides, the damping could be frequency-dependent between the two modes in the experiment. However, the errors around the anti-resonance frequencies could barely affect the configurational optimization using FEA since only performance around resonance frequencies are considered for energy harvesting.

The power FRFs show that when the position of $M_{+2}$ is varied from 6 to 9 , the first two modes becomes in-phase, which the anti-resonance area is moved before the first mode, and the first mode only generate much lower power output than the second mode. When the position of $M_{+2}$ is altered from 5 to 1 , the resonance frequency $\mathrm{f} 1$ of mode 1 is slightly decreased and the resonance frequency $\mathrm{f} 2$ of mode 2 is considerably increased. Since the harvesters with better broadband performance have closer resonance frequencies and relatively large power output in each mode, by assuming the frequency ratio $\mathrm{f} 2 / \mathrm{f} 1$ is smaller than 1.7 and the power output of each mode is greater than $0.1 \mathrm{~mW}$ for these harvesters, the configurations with mass position $\mathrm{P} 05, \mathrm{P} 04$ and $\mathrm{P} 03$ can meet the criteria.

Fig. 9 shows the experimental power output FRF for some typical positions of M+2 when the pos itions of $\mathrm{M}+1$ is fixed at 1 and 2 . Since the effective length of the base layer is decreased, the resonance frequencies of the first two modes are both increased. The preferred mass positions using the same criteria (f2/f1 1.7 and power output $>0.1 \mathrm{~mW}$ ) are P15, P16, P26 and P27. Therefore, the selected configurations from the experimental results actually have a good agreement with the previously mentioned screening results based on the original configurations (see Fig. 4). 


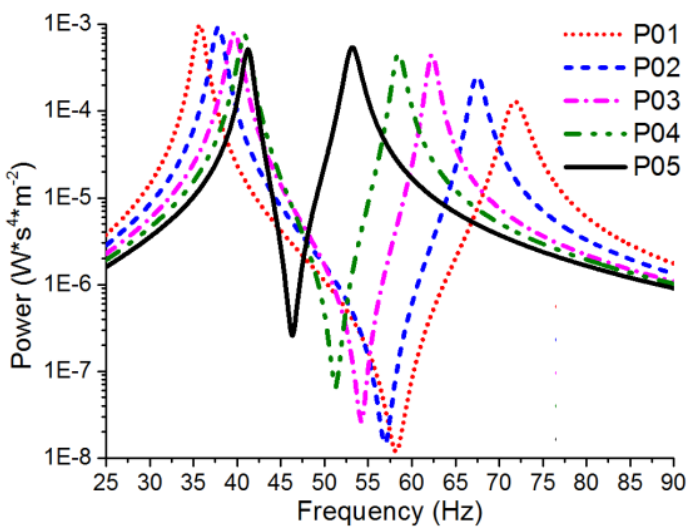

(a)

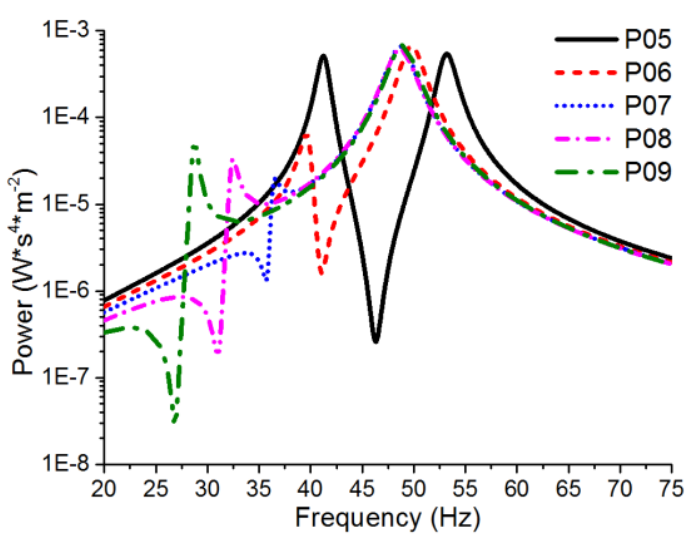

(c)

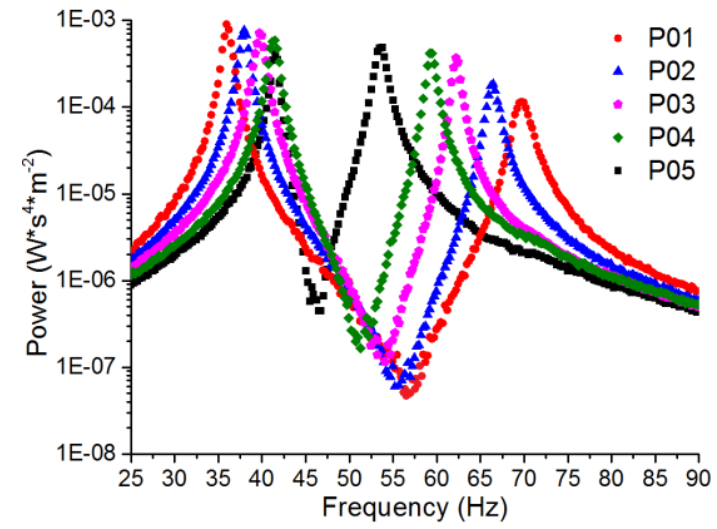

(b)

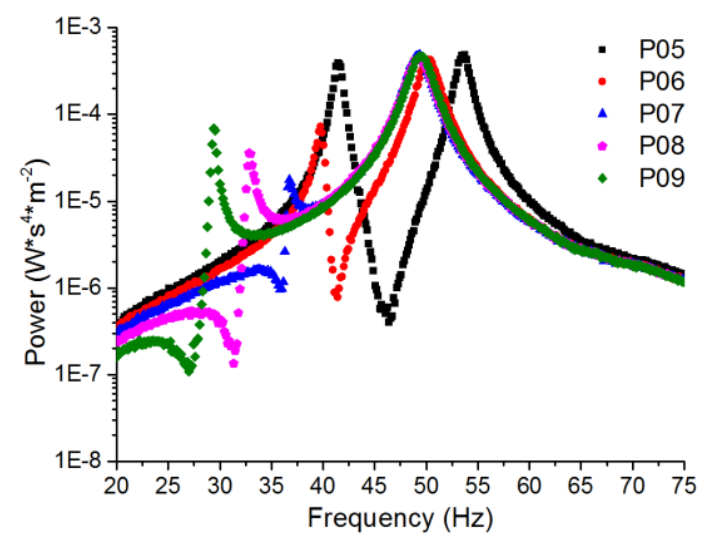

(d)

Figure 8: Comparison of the simulated and experimental power FRF with $100 \mathrm{~K} \Omega$ resistive load for two-layer model $2 L 2 M$ and $M_{+1}=0$. (a) and (c): simulated; (b) and (d) experimental.

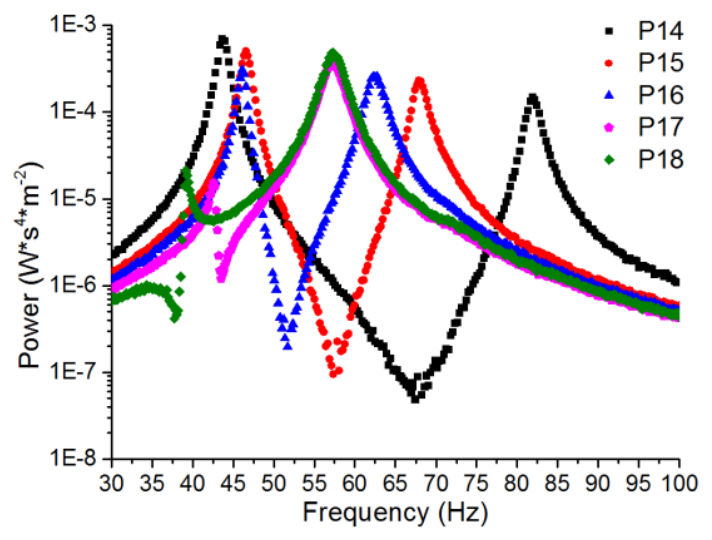

(a)

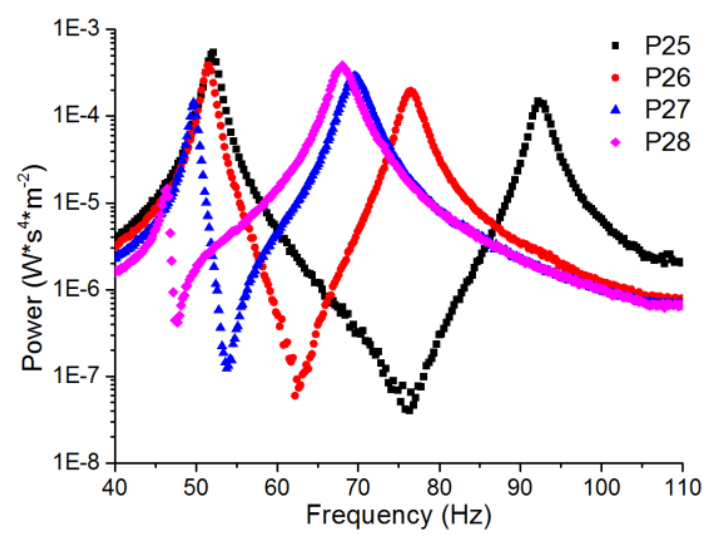

(b)

Figure 9: Experimental power FRF with $100 \mathrm{~K} \Omega$ resistive load for two-layer model $2 L 2 M$. (a): $M_{+I}=1$; (b)

$$
M_{+1}=2 \text {. }
$$


Figs. 10(a) and (b) show the measured voltage FRFs near the two resonance frequencies of mode12L2M-P05 with different resistive loads from $10 \mathrm{k} \Omega$ to $909 \mathrm{k} \Omega$. When the resistance is increased, the voltage is increased, and the resonance frequency is shifted due to the back coupling effect. The voltage only increases slightly when the resistance is larger than $500 \mathrm{k} \Omega$. Figs. 11(a) and (b) show the average power output FRFs around the first two modes of model 2L2M-P05 determined using the measured voltage data. Figs. 11(c) and (d) show the average power output FRFs around the first two modes of model 2L2M-P01.

In general, when the resistive load is increased from $100 \mathrm{k} \Omega$ to $150 \mathrm{k} \Omega$, the harvester generates near-optimal power output in each mode. Since the optimal resistive load is mainly affected by the piezoelectric capacitance and the angular resonance frequency, for different configurations, the modes with close resonance frequencies should have similar ranges of the near-optimal resistance. Therefore, a $100 \mathrm{k} \Omega$ resistive load is used in all experimental tests in this article for the convenience of performance comparison.

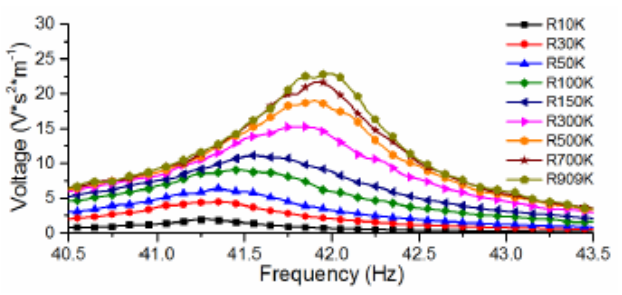

(a)

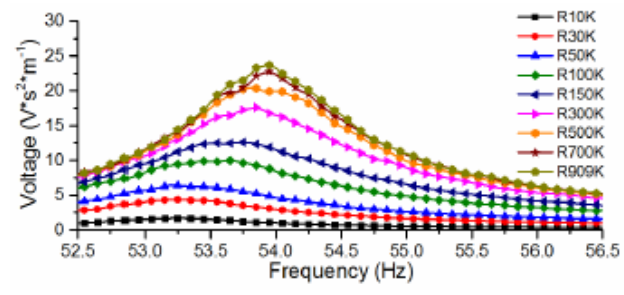

(b)

Figure 10. Experimental voltage FRFs around the first two modes for different resistive loads (e.g. $\mathrm{R} 10 \mathrm{~K}=10 \mathrm{k} \Omega$ resistance) for model 2L2M-P05: (a) mode 1; (b) mode 2.

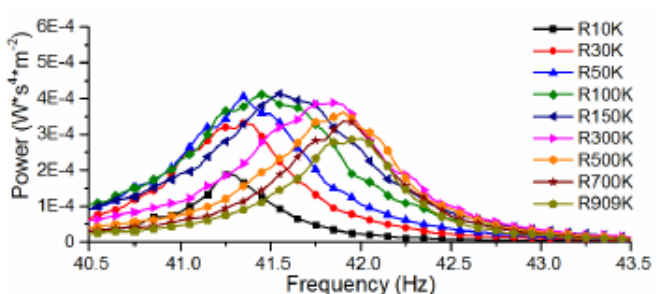

(a)

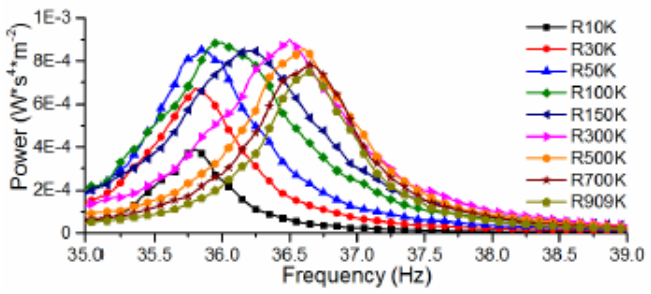

(c)

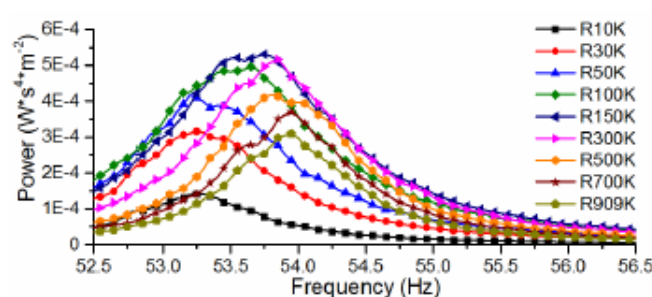

(b)

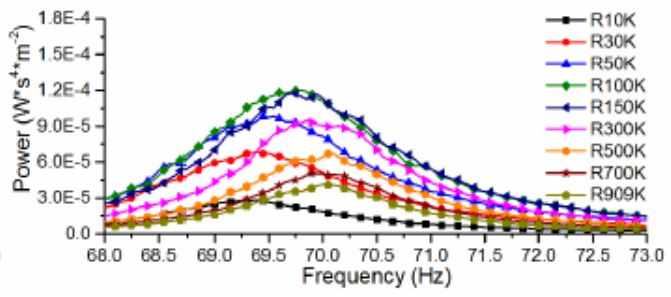

(d)

Figure 11. Experimental power FRFs around the first two modes for different resistive loads for two-layer harvester with mass position P05 and P01: (a) P05 mode 1; (b) P05 mode 2; (c) P01 mode 1; (d) P01 mode 2. 
Fig. 12 illustrates the two measurement points on mode1 2L2M using the laser sensor. Point 1 is to measure the free tip displacement of the base layer (at the clamped end of the upper layer). Point 2 is to measure the free tip displacement of the upper layer. Based on the FEA modal analysis, the maximum displacement of the first modes can be derived from either point 1 or point 2. Fig. 13 shows the measured displacement FRFs around the first two modes of model 2L2M with typical mass positions. The displacement FRFs are measured under short-circuit condition, which means the two electrodes on the top and bottom of the PZT layer are directly connected. When the position of $M+2$ is less than 6 , point 1 indicates the maximum displacement in mode 1 . When the position of $M+2$ is greater than 6 , point 1 indicates the maximum displacement in mode 2. For mass position P06, point 2 always indicates the maximum displacement. When the mass position is varied from P06 to P07, according to the base layer's displacement FRFs, the anti-resonance between the two modes is eliminated, and it is similar to the corresponding power FRF results.

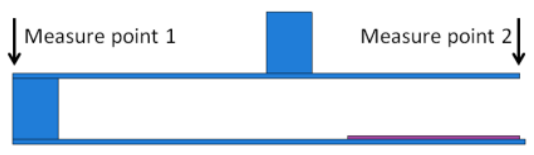

Figure 12: Sketch of the displacement measurement points 1 and 2 on the $2 L 2 M$ model for the laser sensor.

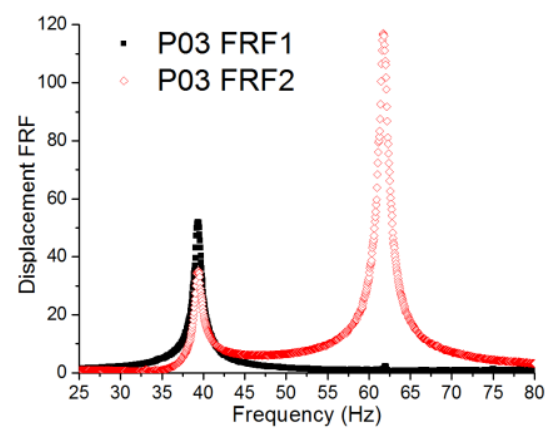

(a)

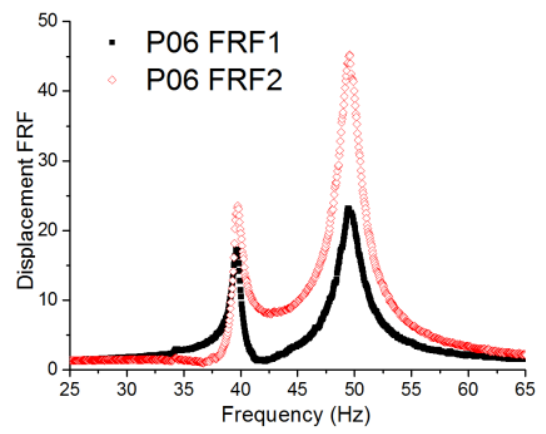

(d)

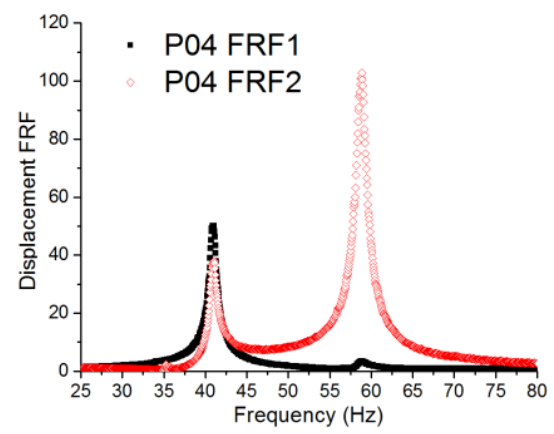

(b)

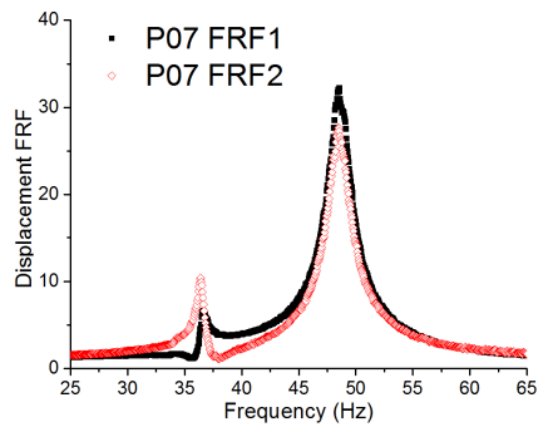

(e)

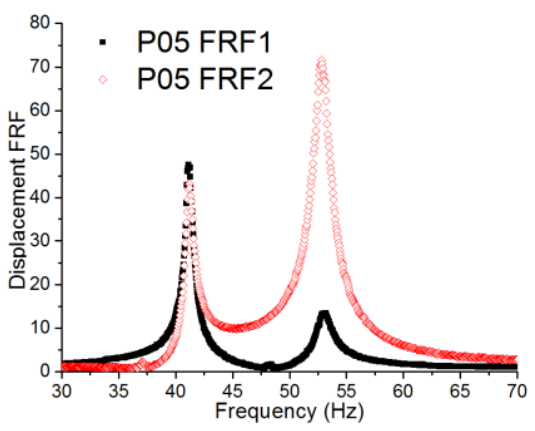

(c)

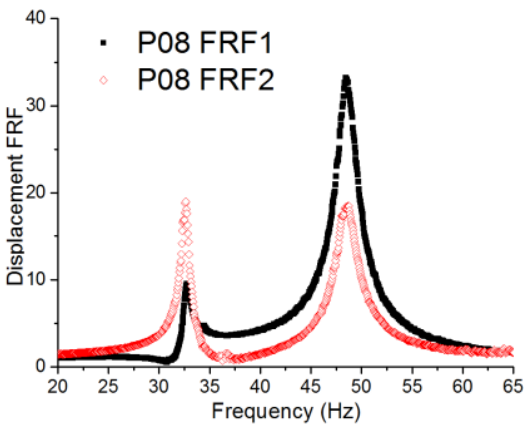

(f)

Figure 13: Experimental displacement FRF of two-layer model 2L2M under short-circuit condition. FRF1: point 1; FRF2: point 2; (a) to (f): P03 to P08. 
Fig. 14 shows some comparisons between the experimental and simulated data of mode12L2M. Fig. 14(a) is the modal participation factor $\gamma$; and the experimental results are derived from the amplitudes of the displacement FRFs at each resonance frequency. Fig. 14(b) is the ratio of two short-circuit resonance frequencies $\mathrm{f} 2 / \mathrm{f} 1$. There are good agreements between the simulated and experimental results for both $\gamma$ and $\mathrm{f} 2 / \mathrm{f} 1$. Table 2 shows the simulated modal mass $\mathrm{m}$, modal participation factor $\gamma$ and mass ratio $\mathrm{N}$. Because $\gamma$ is a quadratic function of $\mathrm{N}$, when $\gamma$ is too small in the first mode for the configuration with mass position from P06 to P09, $\mathrm{N}_{1}$ is significantly small. For the mass positions P04 to P01, although the modal mass of mode 2 is small, $\mathrm{N}_{2}$ is still large enough due to the larger $\gamma_{2}$. Fig. 14(c) shows the EMCC; the experimental results are derived from the short-circuit and open-circuit displacement FRFs. There are larger errors between the simulated and experimental EMCC than the structural data. The errors could be generated by several reasons such as the difference of piezoelectric properties due to the manufacturer, the conductive adhesive used to bond the PZT, the manner of measurement and assembly errors.

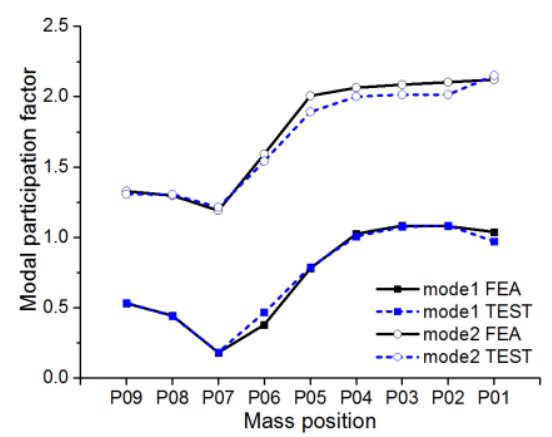

(a)

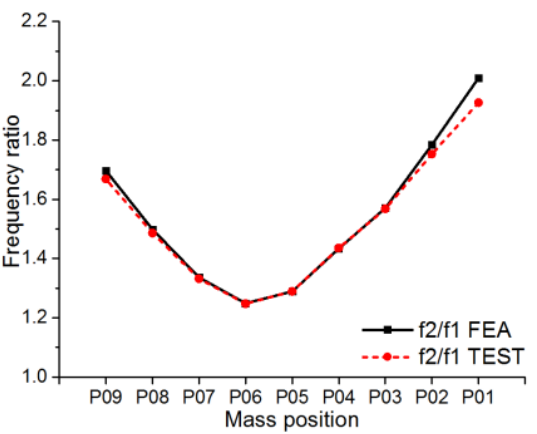

(b)

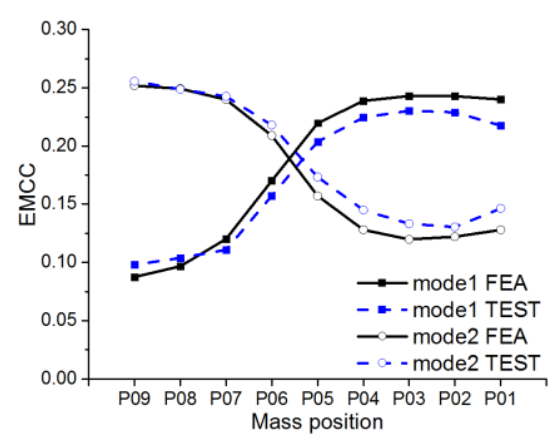

(c)

Figure 14: Comparison between the simulated and experimental results for (a) the modal participation factor;

(b) frequency ratio, and (c) electromechanical coupling coefficient EMCC

Table 2: Simulated modal parameters of two-layer model 2L2M

\begin{tabular}{ccccccc}
\hline Model & $\begin{array}{c}m_{m 1} \\
(\mathrm{~g})\end{array}$ & $\begin{array}{c}m_{m 2} \\
(\mathrm{~g})\end{array}$ & $\gamma_{1}$ & $\gamma_{2}$ & $N_{1}$ & $N_{2}$ \\
\hline P09 & 23.9 & 33.8 & 0.529 & 1.327 & $8.5 \%$ & $75.1 \%$ \\
P08 & 19.5 & 37.2 & 0.443 & 1.298 & $4.8 \%$ & $79.0 \%$ \\
P07 & 16.9 & 46.7 & 0.179 & 1.190 & $0.7 \%$ & $83.4 \%$ \\
P06 & 18.7 & 25.3 & 0.378 & 1.592 & $3.4 \%$ & $80.9 \%$ \\
P05 & 29.8 & 12.1 & 0.779 & 2.006 & $22.8 \%$ & $61.6 \%$ \\
P04 & 29.5 & 8.5 & 1.025 & 2.065 & $39.0 \%$ & $45.6 \%$ \\
P03 & 31.1 & 6.9 & 1.083 & 2.086 & $46.1 \%$ & $38.1 \%$ \\
P02 & 34.2 & 6.1 & 1.079 & 2.103 & $50.3 \%$ & $33.9 \%$ \\
P01 & 38.4 & 5.6 & 1.037 & 2.122 & $52.2 \%$ & $31.9 \%$ \\
\hline
\end{tabular}


In conclusion, according to the experimental results, when the mass positions are varied from P01 to P05, the first mode is largely affected by the base layer. The varied position of $\mathrm{M}_{+2}$ on the upper layer largely affects f2 (see Fig. 8(a)), and the base layer generates larger displacements in mode 1 (see Figs. 13(a)-(c)). Because the amplitude of displacement FRF directly affects the strain generated near the clamped end, which is covered by the PZT layer, mode 1 has larger EMCC than mode 2 (see Fig. 14(c)). Similarly, for the mass positions varied from P07 to P09, the second mode is largely affected by the base layer. The varied positions of $\mathrm{M}_{+2}$ on the upper layer largely affects $\mathrm{f1}$, and the base layer generates larger displacements in mode 2, and mode 2 has large EMCC than mode 1. For mass position P06, the strong interaction between the base and upper layer in both modes generates the smallest frequency ratio (see Fig. 14(b)), close amplitude of base layer displacement and close EMCC.

There are also other factors that can affect the performance of the two-layer harvester. For example, Fig. 15 shows the experimental power output FRFs of the two-layer model with mass position P09 but different magnitudes of mass $\mathrm{M}_{+2}$. The original value of each mass is $18.8 \mathrm{~g}$. When the value of $\mathrm{M}_{+2}$ equals $0 \mathrm{~g}$, the model has only mass $\mathrm{M}_{+1}$. By changing the value of $\mathrm{M}+2$, similar responses can be observed as altering mass positions. When the value of $\mathrm{M}_{+2}$ is from 0 to $4.6 \mathrm{~g}$, the acceptable performance for both two modes can be found.

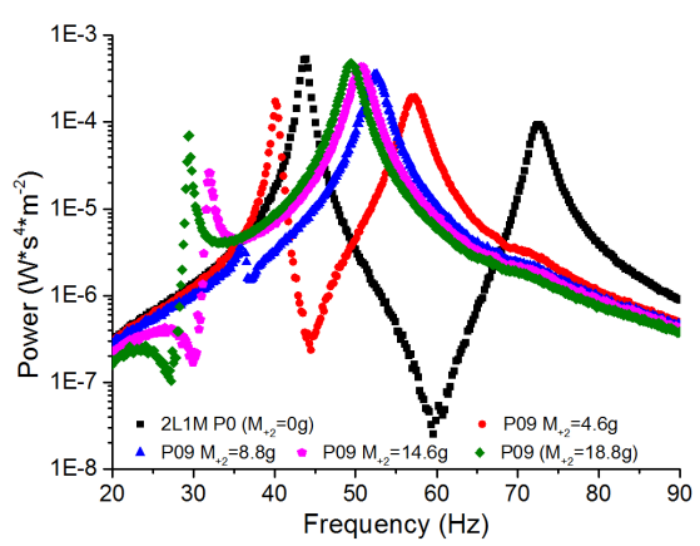

Figure 15: Experimental power FRF with $100 \mathrm{~K} \Omega$ resistive load for two-layer model P09 with different weights $\mathrm{M}_{+2}$.

\subsection{Multi-layer performance}

In this section, the power outputs FRFs of multi-layer configurations are presented. Since there are too many possible configurations, few typical configurations are tested and analyzed. Fig. 16 shows the experimental and simulated power FRFs of some typical one-sided three-layer model 3L3M, which consists of three masses $\left(\mathrm{M}_{+1}, \mathrm{M}_{+2}\right.$ and $\left.\mathrm{M}_{+3}\right)$, two upper layers $\left(\mathrm{L}_{+1}\right.$ and $\left.\mathrm{L}_{+2}\right)$. Fig. 17 shows the experimental and simulated power FRFs of some typical two-sided three-layer model 3L4M, which consists of four masses $\left(\mathrm{M}_{+1}, \mathrm{M}_{+2}\right.$, $\mathrm{M}_{-1}$ and $\left.\mathrm{M}_{-2}\right)$ and one upper layer $\left(\mathrm{L}_{+1}\right)$ and one lower layer $\left(\mathrm{L}_{-1}\right)$.

According to the experimental power output FRFs given in Figs. 16 and 17, if it is assumed that the criteria are: power output in each mode is larger than $0.1 \mathrm{~mW}$ and the ratios of adjacent resonance frequencies are 
smaller than 2, then the mass position P292 for model 3L3M and the mass positions P04-39, P05-39 and P06-39 for model 3L4M can meet the criteria. A good agreement can be found between the simulated and experimental FRFs for resonance and off-resonance conditions. The amplitudes of power outputs in some modes are slightly overestimated in simulation.

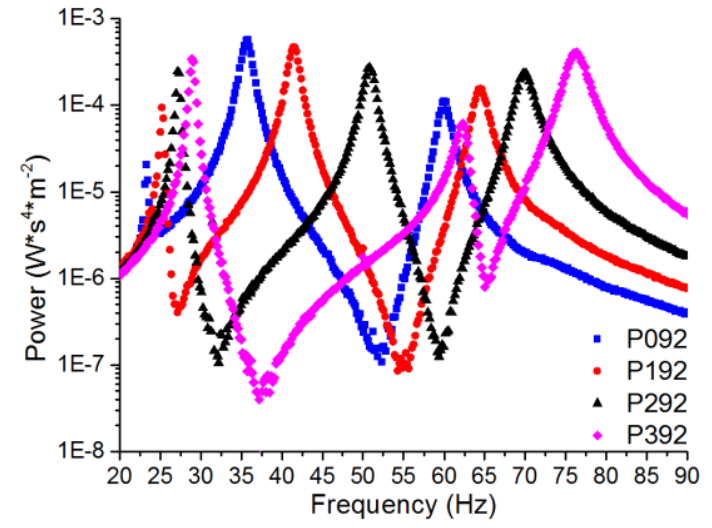

(a)

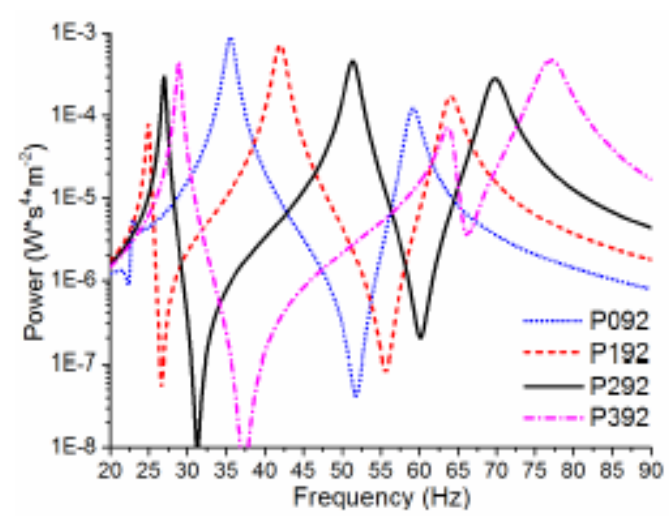

(b)

Figure 16. Experimental and simulated power FRF with $100 \mathrm{k} \Omega$ resistive load for one-sided three-layer model 3L3M with typical mass positions: (a) Experimental; (b) simulated.

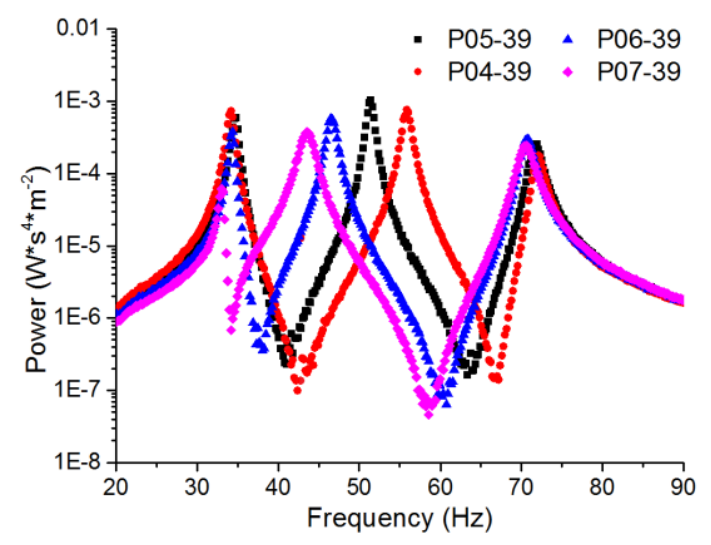

(a)

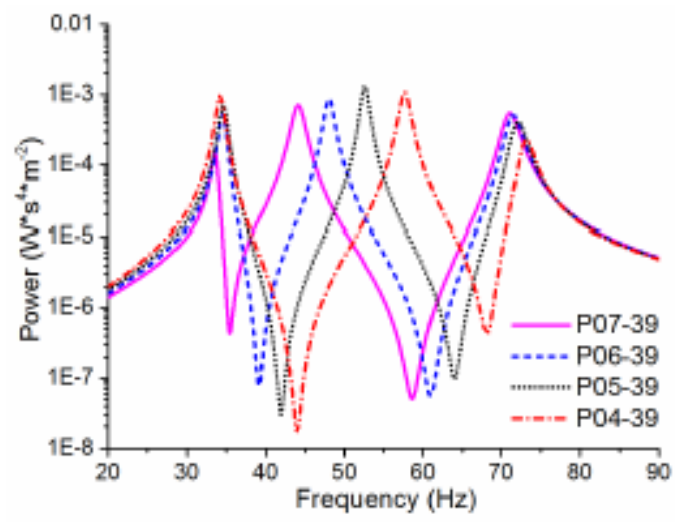

(b)

Figure 17. Experimental and simulated power FRF with $100 \mathrm{k} \Omega$ resistive load for two-sided three-layer model 3L4M with typical mass positions: (a) Experimental; (b) simulated.

In fact, the good agreements between the simulated and experimental results in both Secs. 6.1 and 6.2 also prove that the multi-layer configurations with good broadband performances can be determined by the optimization strategy, which using the ratios of adjacent natural frequencies and mass ratios as two filters to screen the configurations with close resonance frequencies and optimal or near-optimal mechanical performance in multiple modes. Since the natural frequencies and mass ratios can be determined directly by the FEA modal analysis, the optimization strategy obviates the need for full steady-state analysis at the early stage. In other words, the configuration cannot have good broadband performance if the modes are far away 
from each other and mass ratios in some modes are too small. For the multi-modal harvester designs with a lot of possible configurations, using this strategy to identify the configurations with acceptable mechanical broadband performance can significantly reduce the difficulty of analysis and time cost. Once the preferred configurations are chosen, the EMCC of each mode and the full analysis can be taken.

Fig. 18 shows the experimental power output FRFs for three different positions of the four-layer harvesters. For mass positions P191-09 and P291-09, the fourth mode is inactive. The configuration with mass position P391-09 can generate four close resonance frequencies with acceptable performance in each mode. Besides, there are also very small peaks after the third and fourth modes of these power FRFs. They are probably due to the rotational effect produced by the shaker. Actually, if too many layers are used, the performance of a multimodal harvester can be degraded, and this will be discussed with further details in the following section.

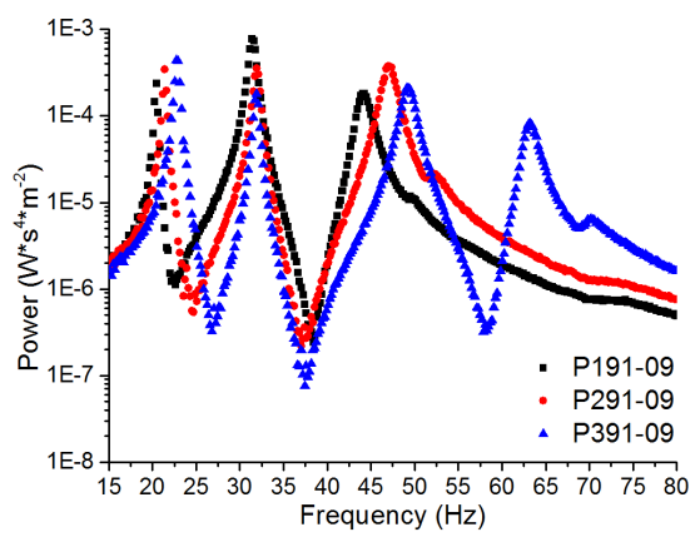

Figure 18: Experimental power FRF with $100 \mathrm{~K} \Omega$ resistive load for one-sided three-layer model 4L5M

\subsection{Bandwidth of multi-modal harvesters}

Fig. 19 shows the comparison of power output between some typical multi-modal harvesters and a single layer harvester $1 \mathrm{~L} 1 \mathrm{M}$ with mass position $\mathrm{M}+1=0$ (a cantilevered beam harvester with a tip mass). Since the multi-modal harvesters can generate close resonance frequencies and relatively large power output in each mode, the effective bandwidth of the power output FRF has been increased in comparison with a single layer harvester. Fig. 18 shows the bandwidth comparison between the single layer and multi-layer models. In Fig. 20 (a), the effective bandwidth is for the minimal power output $10-5 \mathrm{~W}$ per $\mathrm{m} / \mathrm{s} 2$, which correspond to minimal voltage $1.41 \mathrm{~V}$ for $100 \mathrm{k} \Omega$ resistive load. In Fig. 20(b), the bandwidth is for the power output larger than $5^{*} 10-6 \mathrm{~W}$, which correspond to voltages larger than $1 \mathrm{~V}$ due to the $100 \mathrm{k} \Omega$ resistive load. The results show that the two-layer harvester can generate more than 1.5 times wider bandwidth and the three-layer harvesters can have more than 2 times the bandwidth of the 1L1M harvester.

However, the four-layer harvester 4L5M-P391-09 generates narrower bandwidth than the three-layer harvesters do. This is due to several reasons. First, the configuration of the four-layer harvester has not been optimized using the configuration optimisation strategy. Besides, the reduced electromechanical coupling significantly affects the power output. This is probably due to the fact that the PZT layer is only bonded near 
the clamped end of the base layer, which does not have the largest strain distribution for a four-layer harvester. Table 3 shows the experimental EMCC of these multi-modal harvesters. The single layer harvester has the largest EMCC in the fundamental mode. The EMCC of the two-layer harvester in the first two modes are slightly reduced compared to the single layer harvester. The EMCC of the three-layer harvesters are significantly reduced in some modes but are still acceptable. The four-layer harvester generates the lowest EMCC in modes 2 and 4.

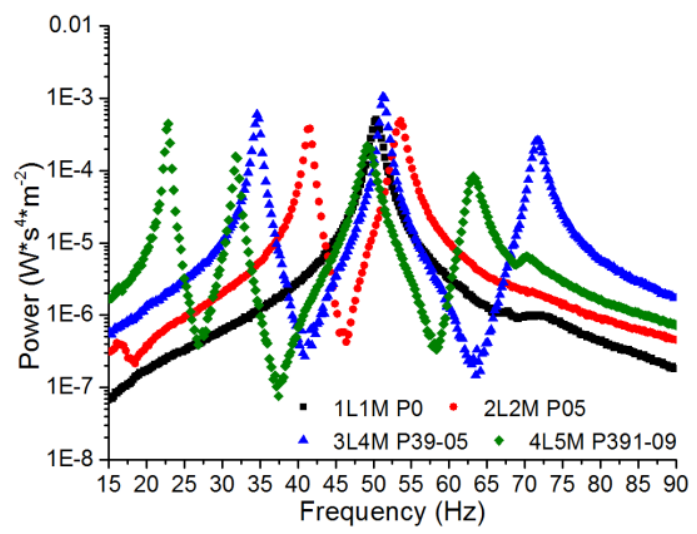

Figure 19: Comparison of experimental power FRF with $100 \mathrm{~K} \Omega$ resistive load.

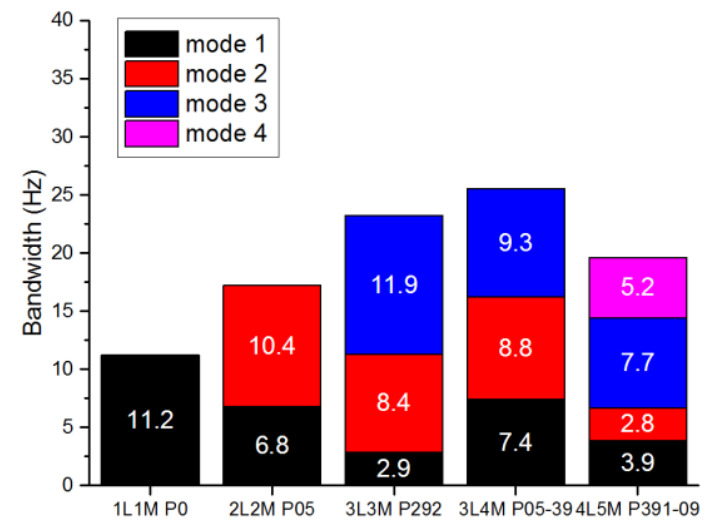

(a)

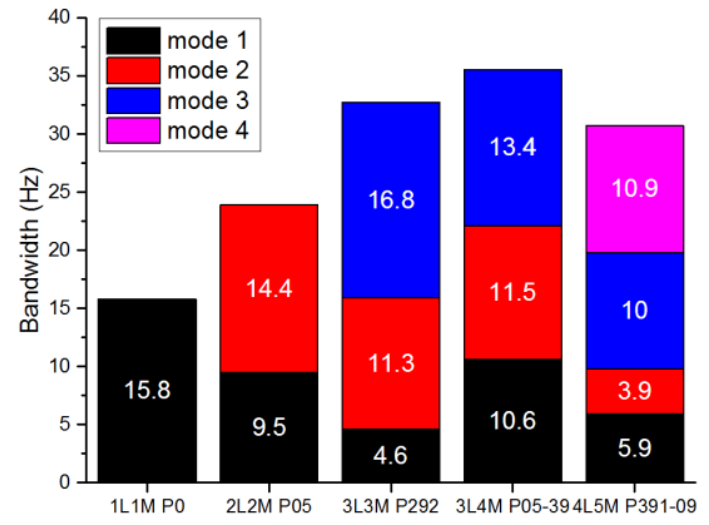

(b)

Figure 20: Experimental bandwidth comparison between the single layer and multi-layer models with $100 \mathrm{~K}$ $\Omega$ resistive load; (a) bandwidth for $1 * 10^{-5} \mathrm{~W}^{*} \mathrm{~s}^{4} / \mathrm{m}^{2}\left(1.41 \mathrm{~V} * \mathrm{~s}^{2} / \mathrm{m}\right)$; (b) bandwidth for $5 * 10^{-6} \mathrm{~W}^{*} \mathrm{~s}^{4} / \mathrm{m}^{2}(1$

$$
\left.\mathrm{V} * \mathrm{~s}^{2} / \mathrm{m}\right) \text {. }
$$

Table 3: Experimental EMCC of multi-layer harvesters in different modes

\begin{tabular}{l|l|l|l|l}
\hline Model & k1 & k2 & k3 & k4 \\
\hline 1L1M P0 & 0.210 & & & \\
\hline 2L2M P05 & 0.204 & 0.173 & & \\
\hline 3L3M P292 & 0.143 & 0.154 & 0.178 & \\
\hline 3L4M P39-05 & 0.199 & 0.156 & 0.123 & \\
\hline 4L5M P391-09 & 0.162 & 0.114 & 0.158 & 0.094 \\
\hline
\end{tabular}




\section{Conclusions}

In this article, experimental studies for the multi-modal harvesters are presented. By altering the mass positions, the fourlayer harvesters are able to generate up to four close resonance frequencies with relatively large power output. The experimental results are compared with the FEA results. The comparison shows that using FEA software can successfully predict the structural and electromechanical performance of the multi-modal harvesters. The experimental results also show that the three-layer harvesters can generate more than two times wider bandwidth in comparison with the single layer cantilevered beam harvester. However, the four-layer harvester generates narrower bandwidth than the three-layer harvesters do due to the significant decrease of EMCC.

\section{Acknowle dgment}

This research is supported by "Beijing Natural Science Foundation (3164050)" and "The Fundamental Research Funds for the Central Universities (2016MS19)", China.

\section{References}

[1] S. P. Beeby, M. J. Tudor and N. M. White, Energy harvesting vibration sources for microsystems applications, Measurement Science and Technology, 17 (12) (2006) R175.

[2] S. R. Anton and H. A. Sodano, A review of power harvesting using piezoelectric materials (2003-2006), Smart Materials and Structures,16 (3) (2007) R1-R21(21).

[3] X. Xiong and S. O. Oyadiji, Modal electromechanical optimization of cantilevered piezoelectric vibration energy harvesters by geometric variation, Journal of Intelligent Material Systems and Structures, 25 (10) (2014) 1177-1195.

[4] J. Zhao, N. S. Goo and D.-H. Ha, Design and performance evaluation of a d33-mode piezocomposite electricity generating element, Journal of Mechanical Science and Technology, 28 (1) (2014) 15-23.

[5] D. Vasic, Y.-Y. Chen and F. Costa, Self-powered piezoelectric energy harvester for bicycle, Journal of Mechanical Science and Technology, 28 (7) (2014) 2501-2510.

[6] M. Ferrari, V. Ferrari, M. Guizzetti, D. Marioli and A. Taroni, Piezoelectric multifrequency energy converter for power harvesting in autonomous microsystems, Sensors and Actuators A: Physical, 142 (1) (2008) 329-335.

[7] S. Qi, R. Shuttleworth, S. O. Oyadiji and J. Wright, Design of a multiresonant beam for broadband piezoelectric energy harvesting, Smart Materials and Structures, 19 (9) (2010) 094009.

[8] W. Al-Ashtari, M. Hunstig, T. Hemsel and W. Sextro, Enhanced energy harvesting using multiple piezoelectric elements: theory and experiments, Sensors \& Actuators A Physical, 200 (4) (2013) 138-146.

[9] Y. Cui, Q. Zhang, M. Yao, W. Dong and S. Gao, Vibration pie zoelectric energy harvester with multi-beam, Aip Advances, 5 (4) (2015) 4495-4498.

[10] Q. Ou, X. Chen, S. Gutschmidt, A. Wood, N. Leigh and A. F. Arrieta, An experimentally validated double-mass piezoelectric cantilever model for broadband vibration-based energy harvesting, Journal of Intelligent Material Systems and Structures, 23 (2) (2012) 117-126. 
[11] W. Zhou, G. R. Penamalli and L. Zuo, An efficient vibration energy harvester with a multi-mode dynamic magnifier, Smart Materials and Structures, 21 (1) (2012) 015014.

[12] X. Han, W. Xu and S. John, A dimensionless analysis of a 2dof piezoe lectric vibration energy harvester, Mechanical Systems and Signal Processing, 58-59 (2015) 355-375.

[13] X. Xiong and S. O. Oyadiji, Optimal design of two-layer vibration energy harvesters using a modal approach, Smart Materials and Structures, 23 (3) (2014) 035005.

[14] A. Erturk, J. M. Renno and D. J. Inman, Modeling of piezoelectric energy harvesting from an L-shaped beam-mass structure with an application to UAVs, Journal of Intelligent Material Systems and Structures, 20 (5) (2008) 529-544.

[15] M. A. Karami and D. J. Inman, Analytical modeling and experimental verification of the vibrations of the zigzag microstructure for energy harvesting, Journal of Vibration and Acoustics, 133 (1) (2011) 011002.

[16] D. F. Berdy, B. Jung, J. F. Rhoads and D. Peroulis, Widebandwidth, meandering vibration energy harvester with distributed circuit board inertial mass, Sensors \& Actuators A Physical, 188 (12) (2012) 148-157.

[17] M. Wu, Y. Ou, H. Mao, Z. Li, R. Liu, A. Ming and W. Ou, Multiresonant wideband energy harvester based on a folded asymmetric m-shaped cantilever, Aip Advances, 5 (7) (2015) 077149.

[18] X. Xiong and S. O. Oyadiji, Modal optimization of doubly clamped base-excited multilayer broadband vibration energy harvesters, Journal of Intelligent Material Systems \& Structures, 26 (16) (2015) 2216-2241.

[19] A. Erturk and D. J. Inman, A distributed parameter electromechanical model for cantilevered piezoelectric energy harvesters, Journal of Vibration and Acoustics, 130 (4) (2008) 041002. 